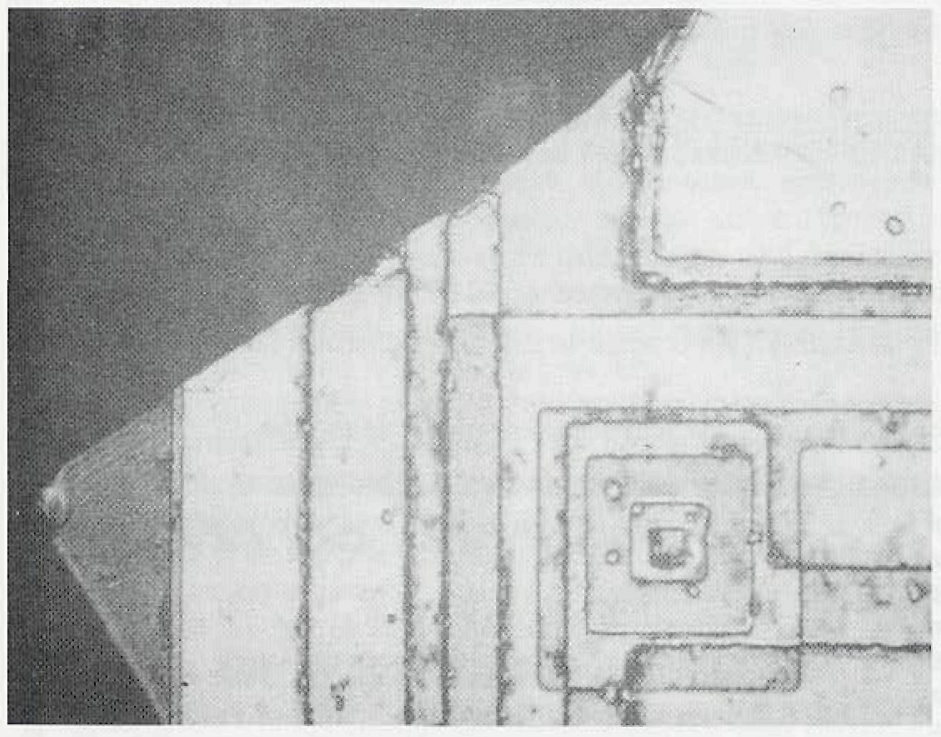

Figure 3: Acoustical image of silicon wafer chip taken at $1 \mathrm{GHz}$.

\section{SOIL TECHNOLOGY, A COMING FIELD AND A NEW MICROSCOPY TO SUPPORT IT}

Sterling P. Newberry, Consultant

A quiet report from an international work shop, this fall in London on World Ecology, points out how primitive our knowledge of basic soil science really is (1). It also records the determination of the participants to bring out the need to study soil in relation to maintaining biodiversity because of man's rapid destruction of global habitat and the inability for soil to recover without it's natural canopy of plant and animal life. It is further pointed out that we have to quickly learn how to reclaim soil, perhaps by artificial means, after insult. The programs they envision will create exciting professional opportunities both for career change and for students over a broad spectrum from basic research to applied engineering. The land fill crises has further underscored the need to find ways to return sewage sludge and other organic waste to useful crop production.

$X$-Ray Microscopy in the ultra soft region has recently been shown to be an ideal tool for studying the complex structure and chemistry of soils (2). This paper by Thieme et. al. at our New Orleans meeting, employed $x$-ray microscopy from a Synchrotron light source. By fine tuning of the wavelength employed, they were able to demonstrate spectroscopically differentiated images of soil components including organic materials in colloidal suspension. They also demonstrated direct measurement of clay mineral pore geometry and volume for the first time. One of the surprising results was that the washing of sludge with detergents binds heavy metals into the soil rather than removing them as expected. Then the vegetables and/or stock feed later extracted the mercury, cadmium etc. for delivery to our tables via our food chain. As the authors point out, the combined resolution and penetration of the soft $x$ - rays cannot be matched by either the optical or electron microscopes in the native, aqueous, living state so necessary for studying soil systems. We look forward to seeing a full publication of this work, since they reported much more than the material given in the extended abstract.

1. Peter Aldhous, Ecologists Draft Plan to Dig in the Dirt, Science 265:1521, September 9. (1994).

2. J. Thieme, J. Niemeyer, P. Guttmann, Colloidal Systems in Soils, MSA Proceedings (1994), p. 64-65.

\section{Seikosha}

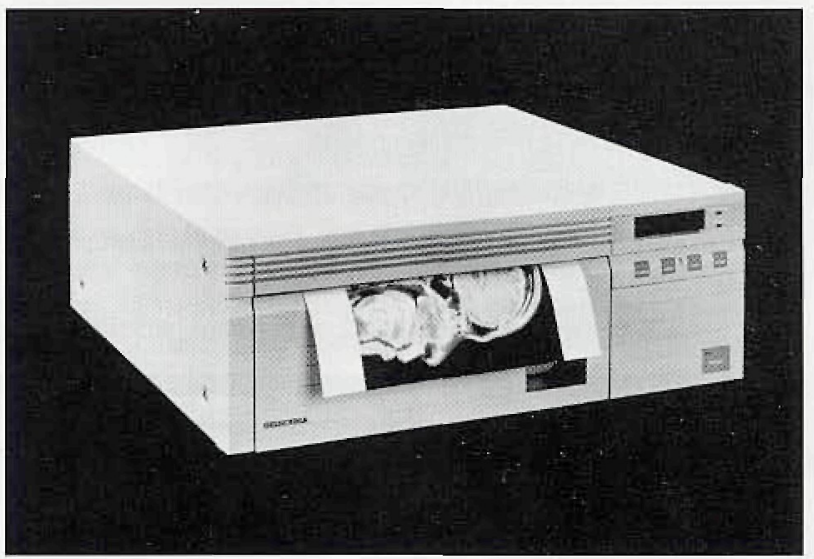

\section{To Seikosha Customers:}

Changes made throughout Seikosha America are allowing Seikosha the opportunity to continue offering the large format VP-4500 and small format VP-1500 printers.

Seikosha looks forward to working with Vital Image Technology as the new Master Distributor for the United States and Canada.

\section{Please contact Vital Image} Technology directly at either their east or west coast offices.

Vital Image Technology offers photographic-quality printers and other imaging related products such as CCD cameras, frame grabbers and scanners. VIT has the imaging solution for both network and stand alone applications

\section{Vital Image Technology}

East Coast Office 800-860-4624 West Coast Office 805-297-5531 
$\checkmark$ Digital Scanning Electron Microscope $\$ 39,500$ installed. Reconditioned AMR SEM's. Philips EM 400 and EM 300 TEM's. Energy Dispersive X-Ray Spectrometers. Complete spare parts Philips TEM's - 200's, 300's and 400's. Call: E. FJELD Co., Inc., 3 Executive Park Drive, No. Billerica, MA 01862. Tel: (508)667-1416. Fax: (508)667-9059.

$\checkmark$ MILITARY RESEARCH LAB IS CLOSING - Military contractor is sell at drastically reduced prices its Sorvall MT-2B ultramicrotome, several Bausch and Lomb stereo microscopes and a Joyce Loebl (Mdl. 3C) and Perkin Elmer (Mdl. 1010G) microdensitometer for measuring minute differences in density changes. For spec. sheets call (202)544-0836.

$\checkmark$ Philips EM300 TEM in good condition. Call: (803)699-8949.

$\checkmark$ JEOL $100 \mathrm{C}$ w/ Kevex 7000 spectrometer. Also Philips / Edax 9100 / 60 X-ray microscope spectrometer. (601)264-9760

$\checkmark$ TEM available for immediate delivery. Philips CM12 with STEM. Used for demonstrations. For additional detail, contact Nathan Little at Philips,

Tel.: (201)529-6165.

$\checkmark$ Coates \& Welter Model 25010-062. with pumps, emission gun, power supply, video input, etc. Working before moved. Make offer. (208)466-6799

\section{emplorment Opportunhtes}

$\checkmark$ Owner of SEM/X-ray \& peripherals seeking alliance with technologist for joint venture. Prefer northwest or mountain states location. Contact Bob at (818)790-6241.

\section{Expand Your Microscopy Horizons with our digitally integrated \\ $x$-ray microanalysis systems \\ Presenting: EDS to fit your Budget! SEMICAPS now supports the Dapple Systems Micro.EDS for PC and MicroPlus for Macintosh.}

For more information, see the Dapple ad in this issue or call Kat at (408) 986-0121 Fax: (408) 986-1059

\section{SEMICAPS Inc.}

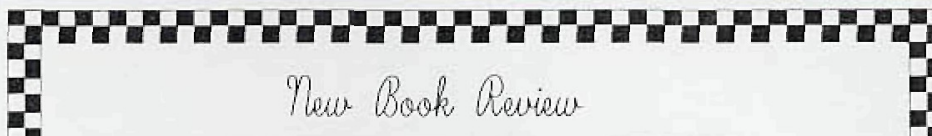

\section{BIOLOGICAL MICROTECHNIQUE J.B. Sanderson, Sir William Dunn School of Pathology, Oxford}

Number 28 of the Royal Microscopical Society Handbooks, 'Biological Technique' is, as we have come to expect from this august body, a veritable mine of information, bang up to date in its methodology. Being considerably larger in pagination than the others in the same series, it covers very well the basics of classical methods of microtomy, including knife sharpening and potential faults. As well as the classical, are up to the minute techniques of microwaving, paraffin and cryostat sections. Arranged in seven chapters viz

Introduction. Collection of material; choice of preparative technique and looking at preparations

2. Fixation. From function and use of fixatives to microwaves in histology and much more.

3. Tissue Processing. Starting with dehydration and proceeding through all the more normal techniques but including newer techniques using Polyethylene Glycol Waxes, Epoxy Resins and Acrylic Resins. With notes on lignified tissues, insect tissues, hair, fibres, diatomes, etc.

4. Microtomy. Detailing types and uses of microtomes, knife types, bevels and facets, angles, sharpening. Wax structure, sectioning technique, and difficulties.

5. Other Preparative Techniques. Covering cytological methods, smears, imprints and replicas; to whole mounts, dry mounts and glycerol jelly mounts.

6. Staining and Dyeing. 28 pages of various techniques and the actions of stains and mordants, nuclear stains, counterstains, with the methodology of their use and the whys! Staining of bacteria, removal of pigments, etc.

7. Finishing the Preparation. From water based to resinous media, coverglass thickness, cleaning of slides and fading of specimens. It is all covered. Also a little section on the restoration of damaged slides which is most interesting.

There are appendices which cover safety and refractive indices. All the chapters are completed with a wealth of references and a wealth of halftone and line illustrations plus tables complete a most useful textbook. Mr. Sanderson is to be congratulated on a well planned and well executed handbook.

Price $\$ 40.00$ (includes shipping and handling). Available from Microscopy Today with payment by check, purchase order or Visa/Mastercard. 